\title{
Design and Fabrication of a Juice Extractor
}

\section{"OMOREGIE, MJ; FRANCIS-AKILAKI, TI; OKOJIE, TO}

\author{
Department of Production Engineering, Faculty of Engineering, University of Benin, \\ P.M.B 1154,Benin City, Nigeria.Email: monday.omoregie@uniben.edu, tina.odibi@uniben.edu, and ojiet@gmail.com
}

\begin{abstract}
This paper focused on addressing the problem of inadequate preservation of farm produce in Nigeria by designing and fabricating a manually operated citrus fruit juice extractor using locally available materials. The extractor produced has the capacity to process $3.8 \mathrm{~kg}$ of oranges at $76.32 \%$ efficiency. The extractor is user friendly, easy to manipulate, maintain and affordable. It is expected that with this machine, the wastage of our farm produce (particularly fruits) will be greatly minimised, thus enhancing improvement in the income generating capacity of fruit farmers, while meeting customers' needs of fresh fruits rich in quality and at affordable prices.
\end{abstract}

DOI: https://dx.doi.org/10.4314/jasem.v22i2.9

Copyright: Copyright (C) 2018 Omoregie et al. This is an open access article distributed under the Creative Commons Attribution License (CCL), which permits unrestricted use, distribution, and reproduction in any medium, provided the original work is properly cited

Dates: First received 22 December 2017; Received in revised form 06 February 2018; Accepted .February 2018

Keywords: Extraction, shaft design, volume of hopper, belt selection, juice

Introduction: Juice extraction has been in existence since thousands of years ago and has been a method for wine production from fruits. For example juice extracted from grape fruits is fermented to produce wine. This has always been by manual process until 1930 when Dr. Norman Walker invented the first juicer. He must have known the benefits of juicing as he lived up to a ripe old age of 108years (Kendhal, 1991). A juicer is therefore a mechanical device that is capable of extracting the juice from fruits, vegetables and leafy greens. Various types of juicers have been developed, depending on the kind of fruit or vegetable to be extracted (Kitinga and Kader, 1996). A lot of tropical fruits are produced in abundance in most tropical nations like Nigeria, to the extent that market supply exceeds demand leading to fall in price during the fruiting season. As a result of this, most of the fruits perish in the market due to inadequate storage facilities, leading to huge losses (Oluwalana, 2011). It is therefore pertinent to find a suitable means of preservation of fruits for economic benefit to the farmers and the generality of our teeming populace.

For year-round production, it may be necessary to part-process raw materials into a form that can be stored in readiness for future processing. Manual juice extractors have been developed for home use due to their limited output (Eyeowa et al., 2017). With the high demand for fruits and allied products, it has become necessary to evolve a means of preserving as well as satisfying the need of domestic and industrial users of the fruits. This paper is therefore aimed at addressing this problem through the design and fabrication of a manual fruit juice extractor suitable for a range of fruits. The juice extractor is being developed as an easily affordable machine that is environmentally friendly, energy efficient and versatile in the processing of fruits. The outcome of this effort will go a long way in providing local alternatives to imported brands of processed fruit juices. This will significantly reduce the amount of fruit being wasted as a result of spoilage. Thus the commercial needs of farmers and customer satisfaction will be met. The focus of this paper is to design and fabricate a manual fruit extractor which can also be motorised, capable of processing juice from fruits within the citrus family found in the tropical region with particular attention to the orange fruit.

\section{MATERIALS AND METHOD}

Material of Construction: In order to avoid Citrus fruit juice contamination resulting from corrosion effects of mild steel, stainless steel was chosen for the shaft, hopper, press cage housing and the press cone. Mild steel (steel with its carbon content up to about $0.25 \%$ ) was chosen for the extractor stand because it is easy to weld and fabricate (Ibhadode, 2001). Due to their low carbon content, they are not hardened by heat treatment process, and as such, weld and heat affected zone (HAZ) do not have hardened zones even though there is quick cooling(Holdren et al., 1997). Mild steel is also known for its good ductility, plasticity which enables it to be easily worked into shapes by rolling, bending or pressing. It has good 
malleability, which enables it to be substantially hammered without too much energy dissipation (Ibhadode, 2001).

Design concept: This work is aimed at achieving optimal and robust design, based on the following calculations which are concerned with the power determination, shaft design, belt selection and determination of the volume of hopper.

Frame: The main requirement in the design of the frame of the machine is that it maintains the proper relative position of the units and parts mounted on it over a long period of service under all the working conditions. The second consideration or requirement is strength. The frame was design to withstand the various weights mounted on it, and it is of dimension $393 \mathrm{~mm}$ X 220mm X 581mm.

Hopper: The hopper was made from stainless steel of $2 \mathrm{~mm}$ thickness. It is a frustum with a conical shape with dimensions as shown in figures 1 and 3 .

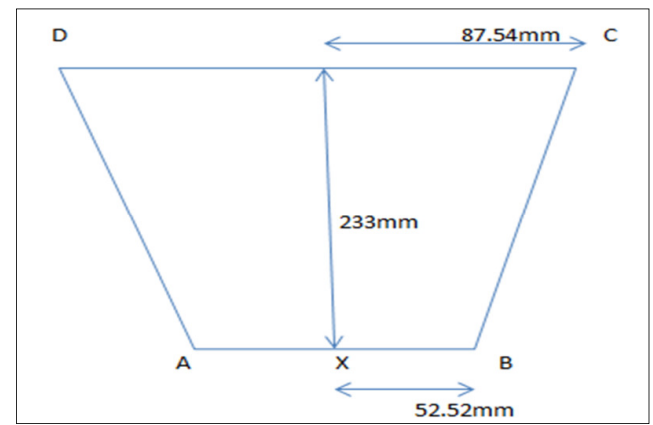

Fig 1: Shape of frustum

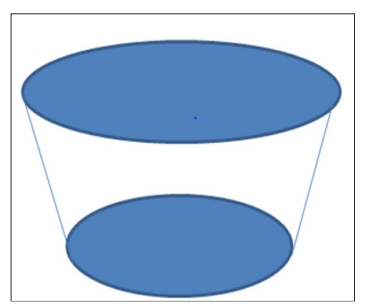

Fig 2: Solid Shape of frustum

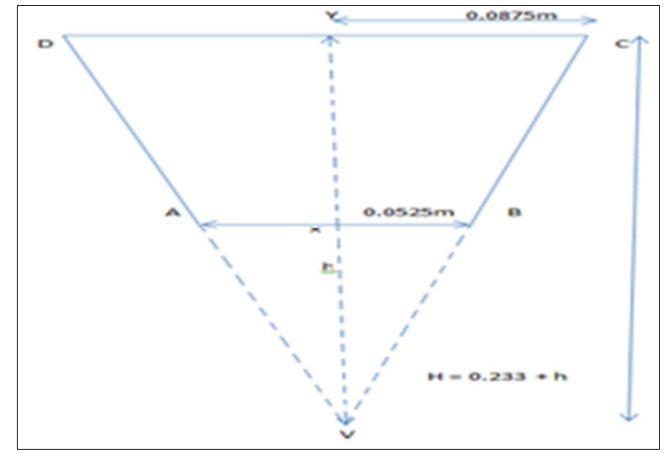

Fig 3: Diagram of the complete Cone from which the Frustum was

obtained

VXB and VYC are similar, thereby using the principle of similar triangles

$\frac{V X}{V Y}=\frac{X B}{Y C} \ldots \ldots . .1$

Equation 1 may be applied in the computation of the frustum as presented in equation 2

$V=V_{2}-V_{1} \ldots .2$

he Perforated Steel Plate: This plate is rigid and made of stainless steel with $4 \mathrm{~mm}$ holes drilled over the whole body at $20 \mathrm{~mm}$ square distance. This perforation acts as a screen during the press operation to filter the juice. The diameter of the barrel was obtained from the CERA classification data for citrus using the thin vessel formula (Deck and Dubowsky, 1994). The applied pressure through the length of the plate due to the constant pressure on the fruit by the screw press acting on the wall was used to determine the appropriate plate thickness.

Bearing: According to Khurmi and Gupta (2005), the equations for calculating basic static load rating $\left(\mathrm{C}_{\mathrm{o}}\right)$ in $\mathrm{Kg}$ for radial ball bearings is given by

$$
C_{o}=f_{o} I Z D^{2} \cos \alpha \ldots . .3
$$

Where $I$ is number of balls in the bearing, $\mathrm{Z}$ is the number of balls per row, $D$ is the ball diameter in $\mathrm{mm}, \alpha$ is the normal angle between the line of action of the ball load and a plane perpendicular to the bearing axis, $\mathrm{f}_{\mathrm{o}}$ is 0.34 for self-aligning ball bearing made of hardened steel (Khurmi and Gupta, 2005), Static equivalent load $\left(\mathrm{P}_{\mathrm{o}}\right)$ is calculated using equation:

$$
P_{o}=X_{o} F_{r}+Y_{o} F_{a} \ldots \ldots \ldots \ldots \ldots . .4
$$


Where $F_{r}$ is radial load, $F_{a}$ is the thrust load, $\mathrm{X}_{\mathrm{o}}$ is radial factor, $X_{o}=0.6$ for radial contact groove ball bearing (Khurmi and Gupta, 2005), $Y_{0}$ is thrust factor; $\mathrm{Y}_{\mathrm{o}}=0.5$ for radial contact groove ball bearing (Khurmi and Gupta, 2005).

Power for Extracting Juice: The power selected for the effective running of this machine is in accordance with a manually operated system, which is $1 / 7$ th of horse power, i.e. approximately 107W, (Khurmi and Gupta, 2005).

Pulley Design: Pulleys and belt arrangement are used to transmit power from a driven shaft. Cast iron has been used in the fabrication of the pulleys for this extractor.

$N_{1} D_{1}=N_{2} D_{2}($ Shigley and Mischke, 1989) $\ldots 5$

Where $N_{l}=$ Speed of Motor $(\mathrm{rpm}), D_{1}=$ diameter of Motor pulley (mm), $N_{2}=$ Speed of Extraction (rpm)

Drive Shaft: It consists of a horizontal conical shaft, flow screw feeder, and pressing core. The material is fed at constant mass flow into the hopper and conveyed horizontally against the wall as cylindrical bowl and between screw feeder/cylindrical cage spaces and against the spring loaded pressing core whose back spring action presses the juice out of the pressed material.

In the Saturation $(30-35) \%$ in accordance with the American society of Agricultural Engineering (ASAE), the average value of rupture strength of a citrus (orange) fruit is given as $421 \mathrm{~N} / \mathrm{mm}^{2}$. Using the above value, the rupture force can be determined from the equation:

$R_{s}=\frac{R_{f}}{A_{m}} \ldots \ldots \ldots \ldots . \ldots$

where $R_{s}=$ Rupture strength $\left(\mathrm{N} / \mathrm{mm}^{2}\right), R_{f}=$ Rupture force $(\mathrm{N}), A_{m}=$ Area of the sliced fruit (orange) mesocarp $\left(\mathrm{mm}^{2}\right)$

Assuming that the sliced fruit (orange) has a conical shape, the surface area of a right circular cone can be determined using equation:

$A_{m}=\pi r l+\pi r^{2} \ldots . .7$

Where $l=\sqrt{h^{2}+r^{2}}$
Then, $A_{m}=\pi r \sqrt{h^{2}+r^{2}}+\pi r^{2} \ldots .8$

Where, $r=$ approximate radius of the cone, $l=$ slant height, $\mathrm{h}=$ height

Torque transmitted by the worm on the shaft: is given by:

$$
T_{w}=R_{f} \times L_{w} \ldots \ldots \ldots \ldots . . . .9
$$

Where: $\mathrm{L}_{\mathrm{w}}=$ length of the worm

Determination of shaft size on the basis of Strength: Neglecting the weight of the shaft, the vertical load acting on it will be:

$W_{1}=T_{1}+T_{2}$ (Total load acting vertically).....10

Torque $T=\left(T_{1}-T_{2}\right) R$,

where $R=\frac{0.05}{2}$ from equation 6 ........11

Moment $M=W \times L=\left(T_{1}+T_{2}\right) L 12$

$\tau_{\max }=\sqrt{M^{2}+T^{2}}$ 13

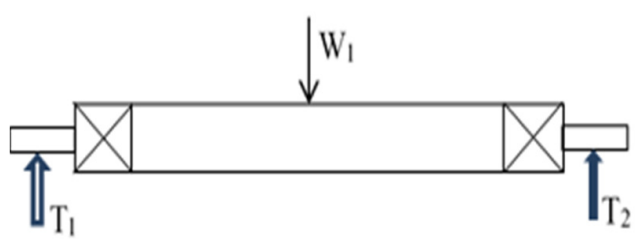

Fig 4: Determination of shaft size using moment diagram

As stated by Khurmi and Gupta (2005), Diameter, $\mathrm{K}_{\mathrm{m}}$ is the numerical combined shock and fatigue factor to be applied, $\mathrm{K}_{\mathrm{t}}$ is the corresponding factor to be applied to the computed torques, $\mathrm{M}$ is the bending moment, $\mathrm{T}$ is torque. For this case, bending moment is negligible. $\mathrm{K}_{\mathrm{t}}$ is equal to 1.0 for rotating shaft with gradually applied loads. Assuming bending moment is negligible, equation is obtained by making shaft diameter the subject of the formula.

$d=\left(\frac{16}{\pi \tau_{\max }} \times T\right)^{1 / 3}($ Khurmi and Gupta, 2005)...14

Recall from equation $6, R=\frac{d}{2}=\left(\frac{16}{\pi \tau_{\max }} \times T\right)^{1 / 3}$

The Speed of the shaft ' $\omega$ ': $R_{f}=M \omega^{2} L_{w} \ldots . .15$

Where, $\mathrm{M}=$ mass of the shaft

From equation $15, \omega=\sqrt{\frac{R_{f}}{M L_{w}}}$ 


$$
R_{f}=M g
$$

By substituting equation 15 into equation 14, we obtain:

$\omega=\sqrt{\frac{R_{f}}{M L_{w}}}=\sqrt{\frac{g}{L_{w}}}$

Belt Selection: A rubber V-belt was used in our design due to the fact that it provides high torque, minimizes power loss and is relatively cheap. Given the power requirement of $1 / 7 \mathrm{hp}$ and with reference to Table 1, type A belt was selected as the most suitable for the design (Khurmi and Gupta, 2005). From table 1 , the belt selected has the following properties; Density of rubber $\dot{\rho}=1590 \mathrm{~kg} / \mathrm{m}^{3}$, coefficient of friction of rubber $f_{1}=0.25$, width of belt $b=$ $0.0127 \mathrm{~m}$, thickness of belt $t=0.0087 \mathrm{~m}$, maximum allowable stress for rubber $\left(\delta_{R}\right)=4 \mathrm{MN} / \mathrm{m}^{2}$, Groove angle $\theta=36^{\circ}$, diameter of big pulley $D_{b}=57 \mathrm{~mm}$, diameter of small pulley $D_{a}=50 \mathrm{~mm}$

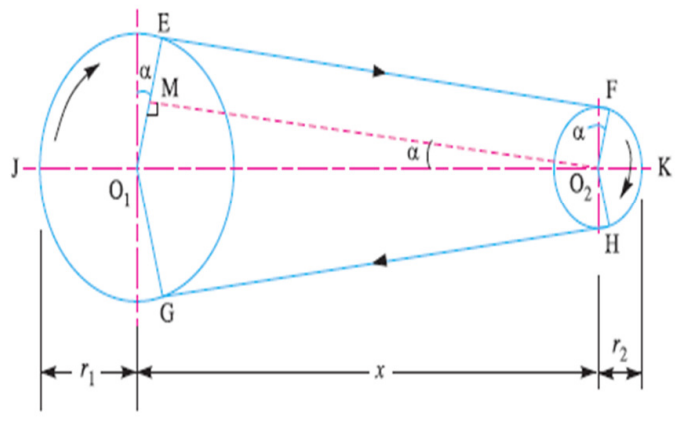

Fig 5: Belt drive arrangement

We obtain Mass per unit length of rubber as $0.175691 \mathrm{~kg} / \mathrm{m}$ using equation 18

$M=b \times t \times \rho$ 18

Belt Speed,

$v=\omega R$. 19

Where $\omega$ and $R$ are the angular speed and the radius of shaft respectively. $\omega=1800 \mathrm{rev} / \mathrm{min}$ (motor specification)

$v=\frac{\pi N D}{60}$

Centripetal force,

$F_{c}=M \times v^{2}$

Centre distance between pulleys

$X=3 D_{a}+D_{b}$

Length of the Belt,
$L=\frac{\pi}{2}\left(d_{2}+d_{1}\right)+2 x+\frac{\left(d_{2}-d_{1}\right)^{2}}{4 x}(\quad$ Khurmi and Gupta,2005)....23

Take $1.5 \%$ less to sustain initial tension ( Khurmi and Gupta,2005). Length of belt,

Angle of Contact, $\beta=\sin ^{-1}\left(\frac{d_{2}-d_{1}}{x}\right)$ (Deck, 1992) 24

Angle of wrap, $\alpha=\pi-2 \beta \quad$ (Deck, 1992)........................25

The Tension of a V-belt can be evaluated using:

$\frac{T_{1}-m v^{2}}{T_{2}-m v^{2}}=e^{\mu \alpha / \sin \frac{\theta}{2}}$ (Khurmi and Gupta, 2005) ...... 26

Where: $\mathrm{T}_{1}=$ tension on the tight side, $\mathrm{T}_{2}=$ tension on the slack side, $\mathrm{m}=$ mass of shaft

But maximum tension on tight side is: $T_{1}=\delta_{R} \times b \times t \quad \ldots \ldots .27$

Where: $\mathrm{b}=$ width of belt $(\mathrm{m}), \mathrm{t}=$ thickness of belt,

$\delta_{R}=$ maximum allowable stress for rubber

Substituting $T_{1}$ into equation 26 , we have

Power required per belt,

$P=\left(T_{1}-T_{2}\right) v$ .28

Substituting values for $\mathrm{T}_{1}, \mathrm{~T}_{2}$ and $v$ above into equation 27 , we obtain:

To determine the number of belts used for the design:

Number of belts $=\frac{\text { Design Power }}{\text { Modified power rating of the belt }}$

(Spotts, 1991) ......29

Efficiency of the machine:

$E_{m}=\frac{\text { mass of properly squeezed orange fruits }}{\text { total mass of fruits }} \times 100$ .30

Where: $E_{m}=$ Machine efficiency

\section{RESULT AND DISCUSSION}

Construction of the juice extractor: The machine is designed for small scale production of any citrus juice particularly orange juice. This production involves 
operations such as facing, turning, boring, milling, welding, cutting, tapping, fillings etc. which can be carried out in any medium size workshop with average machining and fabrication facilities. Other components such as bearings, electric motors, Vbelts, bolts/nuts, etc. were sourced for in the local market. The important workshop facilities required for production of the machines are lathe machine, milling machine, welding machine, hand grinding machine, drilling machine, M10 tap and file. The quality of construction is an important factor in overall performance of any machine. This fact was given due consideration in the selection of the production processes and sequences of operation in the fabrication of the machine.

The extractor was tested to evaluate the performance as follows:

(i) $\quad 3.8 \mathrm{~kg}$ of sliced orange was gradually fed into the juice extractor through the hopper.

(ii) The machine was operated long enough (about 15 minutes) for the juice to be separated from the fiber.

(iii) The processed fruit juice was collected through the outlet channel of the machine.

It was observed that while the machine was working, the noise level and vibration was reduced to an appreciable extent. But the time taken to extract an amount of juice was dependent on the rate of operation, and the power imputed by the operator. Also out of the $3.8 \mathrm{~kg}$ of orange fruit that was fed into the machine, about $0.9 \mathrm{~kg}$ was not properly squeezed.
From this observation, the juice extractor's efficiency was evaluated using equation 29 , and found to be $76.32 \%$.

Design Projections: The isometric and orthographic projections of the juice extractor are shown in figures 6 and 7.

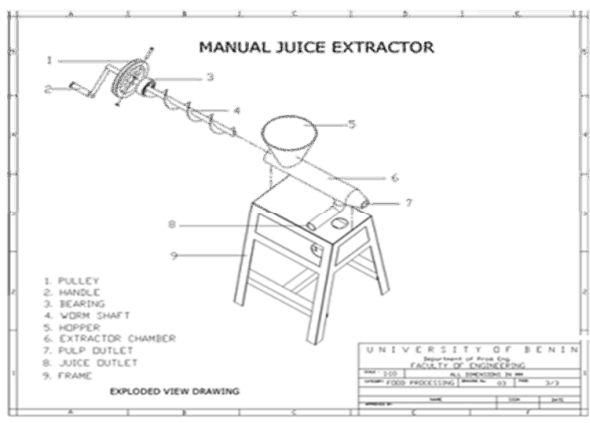

Fig 6: Isometric view of the juice extractor

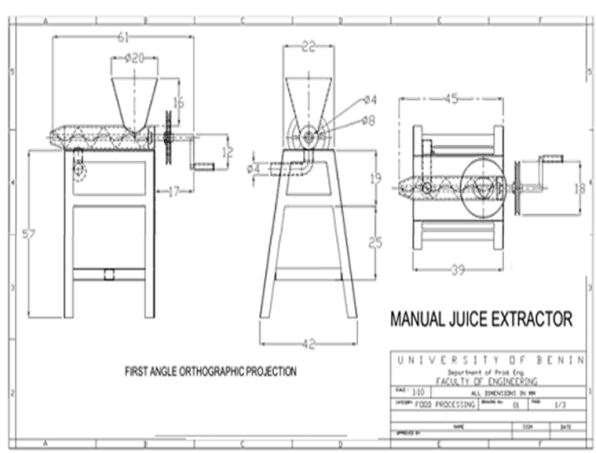

Fig 7: Orthographic projection of the juice extractor

Table 1: Dimensions of standard V-belts according to IS:2494-1974 (Maleev et al.,1983)

\begin{tabular}{cccccc}
\hline $\begin{array}{c}\text { Type of Pow ranges Minimum pitch diameter T op width Thickmess Weight per metre } \\
\text { belt }\end{array}$ & in $\mathbf{k W}$ & of pulley (D) $\mathbf{m m}$ & (b) $\mathbf{m m}$ & (t)mm & length in Newton $N$ \\
\hline A & $0.7-3.5$ & 75 & 13 & 8 & 1.06 \\
B & $2-15$ & 125 & 17 & 11 & 1.89 \\
C & $7.5-75$ & 200 & 22 & 14 & 3.43 \\
D & $20-150$ & 355 & 32 & 19 & 5.96 \\
E & $30-350$ & 500 & 38 & 23 & - \\
\hline
\end{tabular}

\section{REFERENCES}

Conclusion: The benefit of this machine cannot be over emphasized. The fruit juice extractor has been developed as an easily affordable technology that is very suitable for the environment, energy efficient and versatile on fruits. When fully developed to incorporate all stages of fruit processing, this machine has the capacity to revolutionize fruit processing in the country. Although this extractor is a portable machine suitable for a small-scale application, the machine has the potential for adaptation into a large industrial facility.
Deck, J. (1992). "The Dynamics of Spatial Elastic Mechanisms with Clearances and Support Structures," Ph.D. Thesis, Department of Mechanical Engineering, MIT, Cambridge.

Deck, JF; Dubowsky, S. (1994). "On the limitations of predictions of the dynamic response of machines with clearance connections," $J$. of Mechanical Design. Vol. 116 (3), pp. 21-41. 
Eyeowa et al.(2017). Design, fabrication and testing of a manual juice extractor of small scale applications. Current Journal of Applied Science and Technology 22(5): 1-7.

Holdren, RD; Harris, WL; Burkhart, GJ (1997). "Squeezing Juice from Forage". Transaction of the ASAE vol. 15(6): p. 1044-1048

Ibhadode Akii, A. Introduction to Manufacturing Technology, Ambik Press, Benin City, Edo State, Nigeria, 2001.

Kendhal RS; F.A.O production year book 1991 available http://www.en.wikipedia.org/wiki/Juicer, accessed (Feb.2013)

Khurmi, RS; Gupta JK (2005). "Text book on Machine Design", Eurasia Publishing House, New Delhi.
Kitinga, R; Kader, P (1996). Small-scale post-harvest handling practice.

Maleev, V; James, D; Hartman, B (1983). "Machine Design”, CBS Publishers and Distributors.3rd Edition.

Oluwalana, IB (2011). Fruit cultivation and processing improvement in Nigeria. Agriculture journal 5(2): 307-310

Peterka, F; Vacík, J (1992). "Transition to Chaotic Motion in Mechanical Systems with Impacts," $J$. Sound Vibration, 154 (1) 95-115.

Spotts, MF (1991). "Design of Machine Elements", Prentice Hall India Pvt. Limited, 6 Edition. 